\title{
Focus Projection and Default Prominence
}

\author{
Daniel Büring (UCLA) \\ buring@humnet.ucla.edu
}

\section{Introduction}

In this paper I try to eliminate focus projection rules, i.e. rules that define which patterns of $\mathrm{F}$ (ocus)-markers in a phrase structure tree are permitted, and which are not. In section 2 I review the purpose focus projection rules serve, and argue that they comprise two very different aspects, which I call vertical and horizontal focus projection, respectively. The main part of the paper, presented in section 3, shows that the empirical generalizations about vertical focus projection are inaccurate, and that, upon closer inspection, no restrictions on vertical focus projection are required.

In section $4 \mathrm{I}$ then return to horizontal focus projection to show that it can be accounted for in terms of the mapping between accents and focus, hence doesn't require separate syntactic focus projection rules. Taken together, these two arguments suggest that focus projection rules can indeed be dispensed with.

The goal of this paper is not entirely novel, and views and arguments similar to the ones presented here have been given before, in particular in section 6 of Schwarzschild (1999). I mainly try to marshal more evidence, and refine the theoretical proposal given there; a brief comparison with Schwarzschild's proposal is provided in section 5 .

\section{What Are Focus Projection Rules All About?}

\subsection{The Standard View}

For concreteness' sake let us consider the focus projection rules as given in Selkirk (1995), which arguably represents the most common version of focus projection rules. $^{1}$

\footnotetext{
${ }^{0}$ Many thanks to Svetlana Godjevac, Katharina Hartmann, and Roger Schwarzschild for discussing this material with me, and to the audience at the workshop Informationsstruktur Kontrastivt held in Lund in the winter of 2002, especially to Valéria Molnár for making this wonderful meeting possible.

${ }^{1}$ For all intents an purposes, the projection rules found in e.g. Selkirk (1984) and Rochemont (1986) or von Stechow and Uhmann (1986) work entirely equivalent, and I think the same criticisms apply. A discussion of the systems in Gussenhoven (1983)ff., Jacobs (1991/2b) and Drubig (1994) has to await a later occasion.
} 
(1) Basic Focus Rule

An accented word is F-marked. (p.555)

(2) Focus Projection ${ }^{2}$

a. F-marking of the head of a phrase licenses F-marking of the phrase (henceforth: vertical focus projection)

b. F-marking of an internal argument of a head licenses the F-marking of the head (henceforth horizontal focus projection)

Taken together, these rules tell us which distributions of F-markers are compatible with a given accent pattern (under a particular syntactic analysis). To a lesser extent, they allow us to go 'backwards', too: Taking as a starting point that a particular node is F-marked, the focus projection rules tell you which other nodes must be F-marked, too. It doesn't predict, however, which terminal nodes will be accented. For example, if we want to F-mark a VP, the minimal F-pattern allowed is one where all verbal projections - VP, $\mathrm{V}^{0}$ and all intermediate $\overline{\mathrm{V}}$ nodes - are F-marked. But in addition to that, XPs within the VP may be F-marked. And if they are, either their heads, or $\mathrm{V}^{0}$, or both are allowed to bear an accent by the rules in (1) and (2) (as the reader is invited to verify). I will return to this point momentarily.

But how do we know independently which nodes are in fact F-marked; that is, how do we test the predictions of these rules? To that end, we need a theory of F-interpretation, which in Selkirk's rendering consists of two parts. First, an ancillary structural notion, the FOC(us) of a sentence, is defined:

(3) Focus of a sentence (FOC):

An F-marked constituent not dominated by any other F-marked constituent.

The interpretation of FOC(us) corresponds to the popular question-answer test for focus:

(4) FOC Interpretation:

'A wh-question expression focuses a constituent, and an appropriate answer to a wh-question must focus the same constituent.' (p.553)

Second, nodes that are not the FOCus have to meet a Given/Newness condition:

\footnotetext{
${ }^{2}$ In Selkirk (1984), this rule read:

(i) Phrasal Focus Rule

A constituent may be focus if (ia) or (ib) (or both) is true:

a. The constituent that is its head is a focus

b. A constituent contained within it that is an argument of the head is focus. (p.207)
}

As a consequence, the F/non-F status of a head is often optional, and no strict rule of $\mathrm{F}$ interpretation can be formulated. This is remedied in the 1995 version, presumably as a reaction of the extended criticism in Rochemont (1986). 
F Interpretation:

a. F-marked constituent but not FOC: new in the discourse

b. constituent without F-marking: Given

(c. FOC: either Given or new)

We do not need to concern ourselves with the precise definition of Givenness (see Schwarzschild (1999), as well as the notion of c-construable in Rochemont (1986)), since I simply use contexts here in which a word or phrase is Given (with a capital ' $G$ ') if and only if it is uttered in the immediately preceding context.

For the purpose of this paper I will adopt these focus interpretation rules. I am much in favor of the idea to subsume the FOCus interpretation rule (4) under F-interpretation or Givenness in general, as done in Schwarzschild (1999). Obviously, however, any such reduction will eventually have to derive the effects of the FOCus interpretation rule in (4), so for the sake of generality, we may as well stick with its explicit version here. Throughout this paper, I will refer to the focus projection rules and the Focus Interpretation Rules presented in this section as the standard view.

\subsection{What the Focus Projection Rules Encode}

With the technical apparatus in place, let us now ask what the effects of these rules are. First, they allow us to derive the following theorem:

(6) If an XP is F-marked, it contains an accent.

I will refer to this as the 'focus contains accent' theorem. To give an idea of the proof: If an XP is F-marked, $\mathrm{X}^{0}$ must be (vertical focus projection, (2a)); if $\mathrm{X}^{0}$ is F-marked, either (CASE 1) $\mathrm{X}^{0}$ is accented (Basic Focus Rule, (1)), in which case, since $\mathrm{X}^{0}$ is contained in XP, $\mathrm{XP}$ is contains an accent. Or (CASE 2) one of $\mathrm{X}^{0}$ 's arguments, call it $\mathrm{YP}$, is F-marked (horizontal focus projection, (2b)), provided there is one. In that case, if $\mathrm{Y}^{0}$ has itself an argument, the proof starts from the top again, and if $\mathrm{Y}^{0}$ doesn't have an argument, CASE 1 applies. Since in any finite tree with headed daughters only there must be XPs without arguments in them, the proof is complete.

Second, they predict that there will be an uninterrupted path of F-marked nodes between an accented XP and the terminal node dominated by it which bears the accent; call that the 'grounding property' (H.Truckenbrodt, p.c.).

Third, they predict that an F-marked XP must be 'grounded' by its head $\mathrm{X}^{0}$ or a complement of $\mathrm{X}^{0}$, not just by any of its daughters. An F-marked adjunct within, or specifier of, XP is not sufficient to license F-marking on XP. It is mainly this prediction that I will take issue with in section 3. Before doing that, however, let me explicitly mention one function the focus projection rules do not serve. 


\subsection{A Common Misconception}

Let us call a question $\mathrm{Q}$ an $X$-question (where $X$ ranges over constituent names) iff the wh-phrase in $\mathrm{Q}$ corresponds to an $\mathrm{X}$. For example:
a. Who painted the tree?
$\rightarrow$ subject-NP-question
b. What did John do?
$\rightarrow$ VP-question
c. What's new?
$\rightarrow$ S-question
d. Why did Carol bury the dishwasher?
$\rightarrow \overline{\mathrm{S}}$ question

The common misconception can then be stated as follows:

$\mathrm{CM}$ : If $\mathrm{A}$ is a direct answer to an $\mathrm{X}$-question $\mathrm{Q}$, any accenting of $\mathrm{A}$ that licenses F-marking on $\mathrm{X}$ in $\mathrm{A}$ is appropriate.

To emphasize just how common this misconception is, consider the following passage written by an eminent scholar in the collection Focus - Linguistic, Cognitive, and Computational Perspectives (Bosch and van der Sandt, 1999):

"...the theory [Selkirk's;DB] makes the wrong prediction in cases like [(8)]. Following Selkirk's theory, we can pass the focus of the accented predicate on to the VP..., which suggests that the VP sent a book to Mary can be interpreted as new. However, [(8)] would clearly be inappropriate in a context "What did she do?'"

The example in question is (8):

(8) She SENT a book to Mary.

Agreed that (8) is not how one would normally pronounce this sentence as an answer to the question "What did she do?" And clearly, the projection rules do allow VP (or even the entire sentence) to be the FOC(us) of the sentence by projecting the F-mark from $\mathrm{V}^{0}$ through any $\overline{\mathrm{V}}$ s to VP. Yet, the criticism is not justified, since it ignores the fact that for (8)'s F-pattern to be licensed, she, a book and Mary must be Given (by (5b)). Otherwise, they, too need to be F-marked, and hence accented ('focus contains accent'), which would result in the more standard accent pattern in (9) (small caps indicate secondary pitch accents):

SHE sent/SENT a BOOK to MARY.

If on the other hand she, a book and Mary are Given, the original sentence seems indeed fine:

(10) (So Klaus brought a book to Mary. How did Sue react?/What happened when Sue heard about that?) She SENT a book to Mary.

Note that by the FOCus interpretation rule (4), VP is the FOCus here; all terminals except for gave are Given, and the sentence is fine, as predicted by Selkirk's rules. 
To reiterate what the common misconception ignores: $\mathrm{F}(\mathrm{OC})$-marking on $X$ in $\mathrm{S}$ is a necessary condition for $\mathrm{S}$ to answer an $\mathrm{X}$-question. In addition, every non-F-marked constituent in S must be Given. To determine which accent pattern is called for in a particular context, both the FOCus interpretation (question-answer) and the F-interpretation (Givenness) need to be taken into consideration.

By the same token, if we are given a context question and a list of all the expressions that count as Given in that context (as for example through a mini discourse à la (10)), we can predict exactly which nodes in the answer need to be F-marked. ${ }^{3}$

\section{$3 \quad$ Vertical Focus Projection Reexamined}

Now that we have clarified what the focus projection rules do (and what they don't do), and what needs to be taken into consideration when checking their predictions, we should exhibit the same care when examining the accuracy of the restrictions they impose on vertical focus projection. Recall that a phrase can only be F-marked if its head daughter is, and the head can only be Fmarked if either it is accented, or if its complement is F-marked (and hence by 'focus contains accent' - accented). Put the other way around, F-marking on a phrase can never be licensed by an accent on an adjunct or specifier alone. In a slogan:

\section{Restricted vertical focus projection:}

Only heads and arguments can project focus.

Contrast this with a rather unrestricted view of vertical focus projection, such as the one indicated in (12):

(12) Unrestricted vertical focus projection:

Any subconstituent can project focus.

I claim that (12) is actually closer to the truth than (11). How do we go about constructing cases that decide the issue? We simply need to avoid the Common Misconception discussed above. To see if $\mathrm{X}$ can project focus to its mother $\mathrm{Y}$, we need to make sure that i) Y (or some node dominating Y) is the FOCus of the sentence (by the question-answer test), and ii) that all other daughters of $Y$ are Given. In such a situation, a single accent on $\mathrm{X}$ should always suffice to make the sentence felicitous according to the unrestricted vertical focus projection view, whereas it should only do so if X is Y's head or a complement of Y's head according to the standard, restricted view.

Something like the unrestricted view on vertical focus projection in (12) has been proposed in the literature before, in particular in section 6 of Schwarzschild

\footnotetext{
${ }^{3}$ The only indeterminate aspect is whether an F-marked verb will itself bear an accent, if its complement does (hence the optionality of accenting gave in the out-of-the-blue context above).
} 
(1999). Schwarzschild discusses examples of projection from AP to NP, based on earlier work of mine. I will start the discussion with these cases in subsection 3.1. The subsections to follow give a large number of additional cases which, I argue, all support the unrestricted view, too.

\subsection{Projection from AP Attributes}

Let us start with a case that has already been discussed in the literature to argue for an unrestricted view of vertical focus projection:

(13) I know that John drove Mary's red convertible. But what did Bill drive?

a. He drove her BLUE convertible.

b. He drove his MOTORCYCLE.

(Büring, 1996)

Sentence (13) is an object-NP-question, as can be seen, among other things, from the felicity of answer $(13 \mathrm{~b})$. But that means that the object NP her blue convertible in (13a) must be $\mathrm{F}(\mathrm{OC})$-marked. In other words, its representation has to be as in figure 1 .

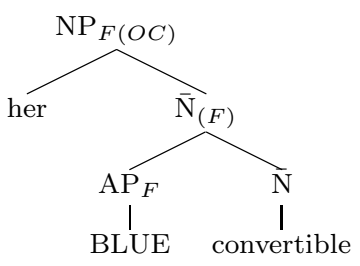

Figure 1: F-projection from AP

But 1 is not a licit F-pattern according to the focus projection rules, because $\mathrm{NP}$ is F-marked, but its head $\mathrm{N}^{0}$ is not (I will leave the question of F-marking on $\overline{\mathrm{N}}$ aside for now; note that $\overline{\mathrm{N}}$ is Given in Schwarzschild's sense, since red convertible is a salient antecedent for $B L U E_{F}$ convertible). Thus, the restricted view rules this example out.

Can't we assign a different F-pattern to (13a), one which is in accord with the focus projection rule? Consider the two candidates in figure 2 :
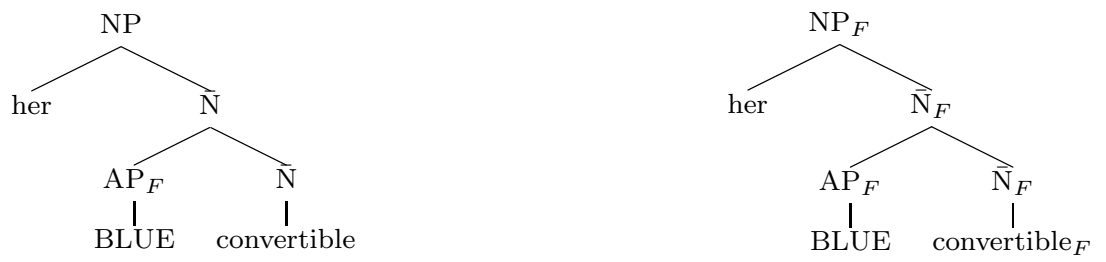

Figure 2: two inappropriate F-patterns

In the left structure, only AP is F-marked, and hence the FOCus of the sentence. This means we have no question-answer match in this structure (the 
question being an object-NP question), in violation of (4). In the right structure, we have a question-answer match, but by the Basic Focus Rule (1), N can't be F-marked without an accent; but accenting convertible is factually impossible in this example: He drove her blue CONVERTIBLE (with or without an additional pitch accent on the AP) is infelicitous as an answer to question (13). So we are left with 1, which in turn constitutes an argument for the unrestricted vertical focus projection view.

Projection from AP to NP is not exotic (provided always that the $\mathrm{N}$ is Given). More examples of this can be found in the literature: ${ }^{4}$

(14) Ann: What did you buy Ben for Christmas?

Clara: I got him a blue SHIRT.

Ann: What did you get for Diane?

Clara: I got her a RED shirt.

(15) (Guess what's up!) An AMERICAN farmer met a CANADIAN farmer.

(16) (Jack said the American President drinks. What did Gilles say?)

He/HE said the FRENCH president drinks.

\subsection{Projection from Transitive Subjects}

Let us consider a second case. While Selkirk (1995) allows (at least some) unaccusative subjects to project focus, she excludes F-projection from true unergative subjects, in particular subjects in transitive constructions. But such projection does exist:

(17) Q: Why did Helen buy bananas?

A: [Because JOHN bought bananas $]_{\text {FOC }}$.

A': [Because John is HUNGRY $]_{\text {FOC }}$

(18) Q: What did Nepomuk say when you accused him of stealing the bananas?

A: [That GWENDOLYN stole the bananas $]_{F O C}$

A': [That he WANTED to PAY for them LATER $]_{\mathrm{FOC}}$

As before, $(17) /(18) \mathrm{A}^{\prime}$ are there to establish that $(17) /(18) \mathrm{Q}$ are indeed IP (or perhaps $\mathrm{CP}$ ) questions (hence the FOC-marking). For concreteness, let us assume that $\mathrm{CP} / \overline{\mathrm{S}}$ is $\mathrm{F}(\mathrm{OC})$-marked here. $(17) /(18) \mathrm{A}$ then show that a subject can F-project to $\mathrm{CP} / \overline{\mathrm{S}}$, provided the VP is entirely Given, cf. figure 3.

A similar example from German is discussed in (Jacobs, 1988) Note that in this example the transitive subject Gerda is adjacent to the verb, since the sentence displays non-canonical object-subject-verb order, with both objects pronominalized: ${ }^{5}$

\footnotetext{
${ }^{4}$ From Delin and Zacharski (1994), Rooth (1992), and Schwarzschild (1999), respectively.

${ }^{5}$ Incidentally, the verb is not Given and hence must be F-marked, too, in this example. We see here a case of horizontal focus projection from a transitive subject.
} 


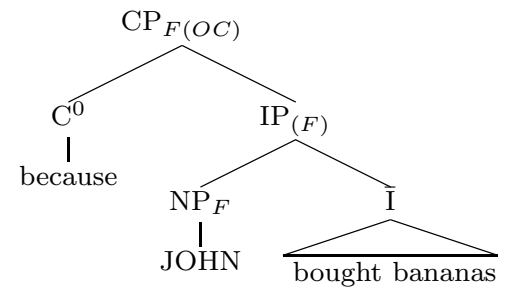

Figure 3: projection from subject

(19) Q: Wo hast du denn den schönen Pulli her? where have you then the nice sweater from

A: Den hat mir [GERDA geschenkt $]_{\mathrm{FOC}}$.

it has me G. given 'How did you get that nice sweater? - Gerda gave it to me.'

\subsection{Projection from Indirect Objects}

Selkirk doesn't explicitly discuss ditransitive constructions, so it is unclear to me whether vertical focus projection from an indirect object is expected. Clearly, the unconstrained view on vertical focus projection predicts it to be possible, correctly, as (20) shows:

(20) Q: Man warf Sinatra vor, er habe der Mafia Geld gegeben. Was hat Dean Martin getan, um nicht auch ein schlechtes Image zu bekommen?

'They accused Sinatra of having given money to the mob. What did Dean Martin do, to avoid having his image ruined, too?'

A: $\operatorname{Er}[\text { hat der HEILSARMEE Geld gegeben }]_{\text {FOC }}$.

he has the salvation army money given

'He gave money to the Salvation Army.'

Once again, the question could be answered by e.g. He invited orphans to Cancun, confirming that the question is indeed a VP-question.

\subsection{Adjuncts}

We have already seen projection from an attribute to N. Similarly, a VP adverbial like a conative PP can project focus to VP, given the right circumstances:

(21) Q: Zur Tatzeit hat Lolek mit seiner Frau einen Einkaufsbummel gemacht. Aber was ist Boleks Alibi?

'At the time of the crime, Lolek was out shopping with his wife. But what was Bolek's alibi?'

A: Bolek hat [ mit seiner TOCHTER einen Einkaufsbummel

B. has with his daughter a shopping stroll 
gemacht $]_{\text {FOC }}$.

made

'Bolek was out shopping with his daughter.'

In this section and the last I have provided German examples. The reason is that indirect objects and VP adverbials usually occur VP-final in English. As a consequence, the nuclear stress placement in the analogous English examples, given in (22), is the same as in an all-new utterance:

(22) a. Dean Martin gave money to the salvation ARMY.

b. Bolek went shopping with his DAUGHTER.

It is hard to be certain that focus on VP projects indeed from the final element, rather than from the direct object or the verb, respectively, in which case the latter would bear a secondary accent. To illustrate, an adherent of the restrictive view on vertical focus projection could argue that (22b) has the F-pattern in figure 4, where arrows mark the path of F-projection.

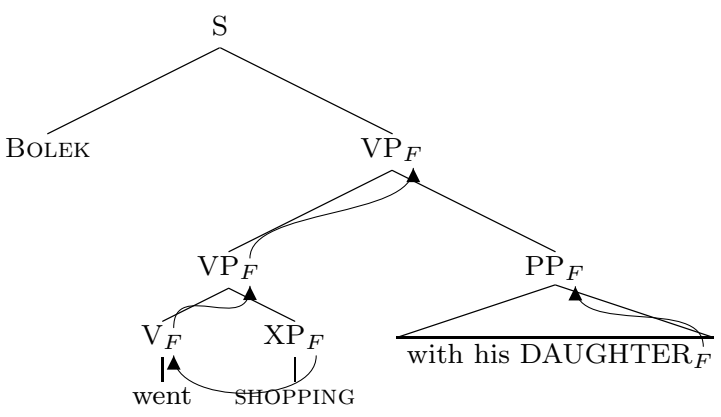

Figure 4: a standard F-projection pattern

To be sure, figure 4 is problematic on theoretical grounds, because V and XP bear F-markers, despite being Given. Yet, if this F-pattern were pragmatically possible, it would sound pretty much the same as the one we argue for, where only PP and the higher VP segment are F-marked. Indeed, it would sound completely the same once we take into consideration that major categories such as the subject and the object will most likely receive a secondary accent even if not F-marked, a phenomenon I proposed to call ornamental accents elsewhere. ${ }^{6}$

In the German examples, on the other hand, it is clear that neither the verbs nor the object, which all follow the accented item in question, bear an additional F-feature, since they are clearly unaccented. If they weren't, their accent, being the last in the sentence, would be clearly perceivable as the nuclear pitch accent. This is shown in figure 5.

So while the English cases, too, show that unrestricted vertical focus projection is necessary, they do so only on the assumption that the Givenness part

\footnotetext{
${ }^{6}$ Büring (submitted); ornamental accents are not accounted for in Selkirk's system, given that the Basic Focus Rule (1) requires that accents always indicate F-marking.
} 
Bolek hat ('B. has')...

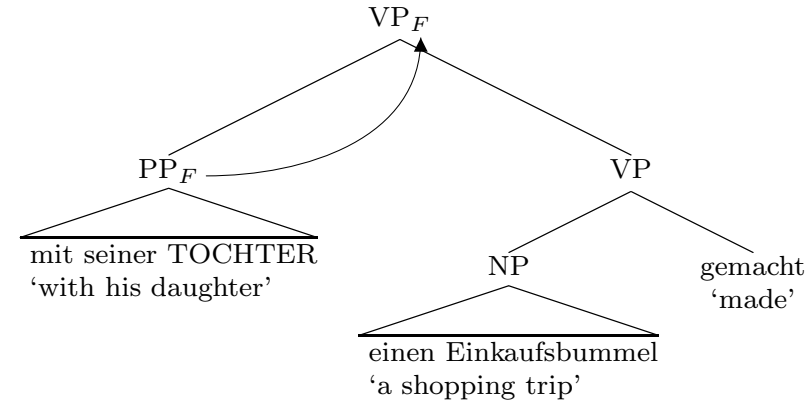

Figure 5: an unrestricted F-pattern

of focus interpretation is right. The German examples make the same point in a more solid fashion; since everything else within the VP is clearly unaccented, there is no other element than the indirect object/adjunct that the VP focus could conceivably be projected from.

\subsection{Projection from Adverbs}

A very similar situation presents itself with simple adverbs; again, the English example only drives home the point if we are willing to accept that the verb call, accented or not, cannot be F-marked, because it is Given:

(23) a. What will she do if she her call doesn't go through?

A: She'll [call him AGAIN $]_{\text {FOC. }}$

A': She'll [call her MOM $]_{\text {FOC }}$.

A": Sie wird [ ihn NOCHMAL anrufen ]FOC.

she will him again call

The German example, once more, is unambiguous in this respect: $\mathrm{V}$ is obviously unaccented, i.e. the VP-focus (and this is VP-focus, witness A') must be projected from the adverb nochmal, 'again'.

The case become equally strong in English if we turn our attention to VPinitial adverbs. The why-question demands an IP/CP-focus answer (you could answer: because I needed to be there in TIME), but since verbs and objects are all Given, only the adverb never is accented; evidently, it can project F vertically as well:

(24) Q: Why were you so upset about missing the bus?

A: [Because one should NEVER miss the bus]FOC.

(25) Q: You bought yourself flowers. I'm puzzled. Why?

A: [Because YOU NEVER bring me flowers/do]Foc.

\subsection{Projection from Minor Categories}

Consider (26): 
Q: Your competitor has lowered the prices on every other model. What do you plan to do to answer that?

A: We will [lower the prices on ALL models $]_{\mathrm{FOC}}$.

A': We will [emphasize the quality of our SERVICE $]_{\mathrm{FOC}}$.

At the very least, Q is a VP-question (cf. A'). And evidently, the answer displays F-projection from the determiner, a minor category.

According to much current theorizing, though, the determiner is indeed the head of the argument nominal, the DP. So in accordance with Selkirk's projection rules, it can project $\mathrm{F}$ to $\mathrm{DP}$, from there to $\mathrm{V}$, and on to $\mathrm{VP}$, as required. One may or may not find this analysis plausible. We note, though, that other minor categories seem to likewise be able to project $\mathrm{F}$ :

(27) Q: What will she wear if I make her return my sweater?

A: She'll wear [her OWN sweater $]_{\mathrm{FOC}}$.

(28) Q: Bill has worn his anti-nuclear power shirt before. Why was he arrested this time?

A: [Because he was wearing ONLY his anti-nuclear power shirt $]_{\text {FOC }}$.

So at the very least, it seems that no argument in favor of the restrictive view on vertical focus projection is forthcoming from these minor categories. If some of them are indeed non-heads, we have another instance of projection from an adjunct.

\subsection{Projection in Headless Structures}

It seems that either conjunct in a coordinate structure is capable of projecting $\mathrm{F}$ to the coordination as a whole. For the final conjunct this may be unsurprising, if you think that it is the complement to the head, the coordinator (besides, it could again be argued that some secondarily accented category to its left is really the origin of F-projection). However, no analysis I know of assumes that initial conjuncts are complements or heads in these constructions; yet, they, too, can project focus:

(29) Q: What will you do if Bill doesn't want to be hooked up with Mary?

A: I'll [hook up JOHN and Mary $]_{\mathrm{FOC}}$

A': I'll [give him his MONEY back] $]_{\mathrm{FOC}}$.

\subsection{Direct Projection from Arguments}

Let me finish with a somewhat more involved case, illustrated by (30):

(30) Q: What did Sue do when you teamed up with Bill?

A: She/sHe [teamed up with $\mathrm{JOHN}]_{\mathrm{FOC}}$.

A': She $\left[[\text { CALLED her MOM }]_{\mathrm{FOC}}\right.$.

A": She [asked JILL and ME to team up $]_{F O C}$. 
Answer A looks innocent enough, because its accent pattern is compatible with projection from NP to V to VP. But note that team up is Given (cf. A"), and as such must not be F-marked. But without F-marking on the head, there can be no F-marking on the projection, according to the restrictive view. Indeed, a sentence like this appears to be predicted to be ineffable: There is no F-marking pattern that conforms to F-interpretation (in particular: leaves the V F-less) and the projection rules.

On the unrestricted view, no problem arises, as the F-pattern can be assumed to be as in figure 6 .

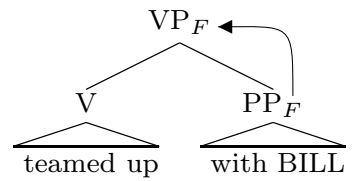

Figure 6: direct projection from an argument (impossible on standard view)

\subsection{Discussion}

It seems to me that the judgements presented in this section so far are uncontroversial. Applying Selkirk's own criteria carefully leads us to recognize that horizontal focus projection is possible from every subconstituent. Which subconstituent(s) end(s) up being the accented one(s) depends solely on their Givenness status.

A conceivable reaction to my argument is, though, that all these examples involve some sort of contrastive focus, and therefore have no bearing on the issue of focus projection, which, after all, regards 'normal', non-contrastive focus.

There are two variants of this position. Variant 1 holds that in addition to 'normal' focus, there is a genuine grammatical category of contrastive focus, and that moreover, contrastive focus and normal focus each have their own projection rules, of which the ones pertaining to normal focus are restrictive in the sense of the standard view. ${ }^{7}$ To evaluate this variant would require a concrete theory that provides criteria to tell us which kind of cases are not contrastive foci, and what their projection behavior is; pending that, nothing more can be said about it here. ${ }^{8}$

\footnotetext{
${ }^{7}$ Contrastive and 'normal' focus may remind the reader of É. Kiss (1998)'s Identificational and Informational Focus. Kiss' position, however, is not that the two are distinguished variants of free, intonationally marked focus, but rather that informational focus is the result of a specific, syntactic configuration. I would indeed venture to say that only Kiss's Informational Focus is focus in the sense most commonly used in the literature, whereas her identificational focus should perhaps more aptly be called 'identificational construction' or some such thing.

Rochemont (1986)'s Presentational Focus and Contrastive Focus are claimed to be different in terms of their interpretation (presentational focus corresponding roughly to Selkirk's F-features, contrastive to her FOC), but, as far as I can determine, not in terms of their realization or projection behavior.

${ }^{8}$ Proposals that recognize a genuine contrastive function of focus such as van Deemter (1999); Fintel (1994); Rooth (1992) tend to be remarkably silent on the question of how such
} 
Variant 2 holds that all focus is contrastive, i.e. that the interpretation of $\mathrm{F}(\mathrm{OC})$-features in terms of Givenness and question-under-discussion is mislead. I am quite sympathetic to this variant, but I also find it hard to distinguish between it and a Givenness-based view of focus. On the 'all focus is contrastive' view, say, blue is contrasted with red in the frame (he drove) her $X$ convertible in (13a), on the latter, all of (he drove) her $X$ convertible is Given, but blue is not. Rather subtle and involved arguments would be required to tease these two points of view apart, or even show that they are essentially different. Importantly, though, I strongly suspect that the contrastive view, too, would wind up with an unrestricted view on vertical focus projection; and that, after all, is really all I am arguing for here.

In sum, then, I claim that there are no restriction on vertical focus projection to speak of. The data we have seen in this section are compatible with a rather more general version of vertical focus projection, which for the moment we can formulate as in (31):

$$
\text { F-marking on X licenses F-marking on any category Y dominating X. }
$$

Note that (31) also does away with the 'grounding property', discussed in section 2.2: There does not need to be an uninterrupted chain of F's from the highest, FOC, to some terminal one. All that is required is that FOC dominate some $\mathrm{F}$ at all. That means that many of the intermediate F-marks which I have put in parentheses in the trees above are in fact no longer assumed to be there.

I chose this version over the more conservative one according to which Fmarking can only project from (any) daughter to mother because independent evidence for intermediate F-markers is very hard to find, and because (31) ultimately allows us to do away with F-projection, and indeed F-marking, altogether, a point I will return to in section 5.

\section{Horizontal Focus Projection}

In the previous section I have argued for (31), which allows F-marking on any non-terminal which dominates another F-marker in turn. Coupled with the Basic Focus Rule (1), this predicts that any F-marked constituent — phrase or word alike - contains an accent. And indeed, for all of the case discussed in section 3, this prediction is correct. However, it isn't in all cases; where it isn't, we speak of horizontal focus projection:

Horizontal Focus Projection: In configuration [ A B ], one of A, B can be unaccented, even though it must be F-marked according to Focus Interpretation

For example, functional elements such as determiners, auxiliaries, or certain adverbials typically remain accentless even if, according to Givenness, they are

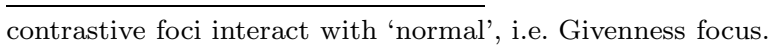


in focus. One might be tempted to explain these cases away by assuming that all these 'light words' are inherently Given. While perhaps feasible in these cases, we note that even contentful lexical expressions such as verbs can be unaccented, despite F-marking, when adjacent to an accented argument. More generally, we see this kind of horizontal focus projection between (unaccented) predicates and their (accented) complements (Fuchs, 1976; Schmerling, 1976; Gussenhoven, 1983, 1992, 1999; Jacobs, 1991/2b, 1992, 1999; Uhmann, 1991):
a. (news headline) $\left[\mathrm{JOHNSON}_{\mathrm{F}} \text { died }_{\mathrm{F}}\right]_{\mathrm{FOC}}$
b. (What's that noise in the background?) $\left[\mathrm{A} \mathrm{DOG}_{\mathrm{F}} \text { is barking }\right]_{\mathrm{FOC}}$.
c. (all new) [I went $_{\mathrm{F}}$ to IRELAND $]_{\mathrm{FOC}}$
d. (What did they do?) They $\left[\operatorname{knocked}_{\mathrm{F}} \text { the } \mathrm{DOOR}_{\mathrm{F}} \text { shut }_{\mathrm{F}}\right]_{\mathrm{FOC}}$.
e. (Why are you in such a hurry?) [I've got a PLANE $\mathrm{F}_{\mathrm{F}}$ to catch $\left._{\mathrm{F}}\right]_{\mathrm{FOC}}$.
f. (Why are you late?) [I met a GIRL $_{\mathrm{F}}$ I knew $]_{\mathrm{FOC}}$.

Such cases can be captured by a horizontal focus projection rule akin to Selkirk's (2b) above, which allows F-marking to 'jump' from an argument to a predicate (note that arguably not all cases in (32) involve internal arguments, but they all can be argued to involve a predicate-argument relation).

I'd like to pursue a slightly different kind of analysis, though, in which horizontal focus projection is an effect of the way prominence, rather than focus, is standardly assigned. In a nutshell, if a larger constituent is to be made prominent, this is generally not done by assigning maximal prominence to each and every word (or syllable) within that constituent, but rather by assigning a default pattern of relative prominence across that constituent. And the default pattern for English (and other Germanic languages including Dutch and German) happens to be such that predicates don't receive a pitch accent if their argument(s) do.

To have a neutral name for the phenomenon in question (neutral as to whether it is focus related or prominence related), I will henceforth adopt from Jacobs (1991/2b, 1992) the term integration; thus all of (32) are assumed to be cases of integration of a predicate with its argument.

It is not the purpose of this paper to develop an adequate theory of integration, i.e. to predict exactly when it can or cannot happen. I will merely, for the purposes of illustration, sketch a system that is, as far as integration/horizontal focus projection is concerned, empirically roughly equivalent to the standard view, but does not rely on focus projection rules. Before I do, though, let me make it clear what the crucial difference between such an approach and an approach invoking horizontal focus projection is.

\subsection{An Argument for a Prominence-Based Theory of In- tegration}

Prominence can be found in the absence of focus. The prominence-based account to integration - regardless of any of its specifics - predicts that the same patterns of accent-placement will be found absent of focus. To give an example, 
it has been observed that a sentence with 'normal intonation' as in (33) can be used to answer questions as different as 'Who did the lawyer send the request to?', 'What did the lawyer do?' or 'What happened?', indicating that its accent pattern is compatible with object-, VP-, and S-focus, respectively:

(33) The LAWYER sent the REQUEST to their OFFICE.

Note crucially that we are talking here about the entire accent pattern, i.e. the nuclear accent on office as well as the pre-nuclear, secondary accents on request and lawyer. If (33) answers the question 'What did the lawyer do?', the verb, both objects, and the VP are by hypothesis F-marked (the former three because they are not Given, the latter because it is the question-answer FOCus). The verb remains unaccented due to integration (a.k.a. horizontal focus projection), since its direct object the request is F-marked. So far so good.

Notice next that this accent pattern pertains if this sentence is used as an answer to the question 'Where did the lawyer send the request?', i.e. a case where it displays PP focus. What governs the distribution of prenuclear accents here? Clearly not the focus projection rules, since nothing except the indirect object is F-marked. Rather, it must be the way prominence is distributed by default among verbs and their objects.

The same argument can be made with the following variation on (33):

A LAWYER I know sent the REQUEST to sell my HOUSE to their OFFICE.

Here, I've added two embedded clauses; in both, the predicates remains unaccented while their arguments (lawyer and house, respectively) are accented. Again, this is the way the sentence would be pronounced both out-of-the-blue as an answer to 'What happened?', or when answering 'Where did the lawyer you hired send the request to see the records?' In the latter case, that would be a rather long-winded and artificial answer, but if you were to give that answer, that is how it would be pronounced: The predicates remain unaccented when their arguments are accented.

To conclude the argument, note that predicates that typically do not integrate when part of a larger focus do also not integrate when in the background:

a. What made them suspect you?

(i) That I know a LAWYER.

(ii) \#That I gambled with a LAWYER.

(iii) That I GAMBLED with a LAWYER.

b. Why were you arrested?

(i) Because I sold the HOUSE.

(ii) \#Because I smoked in the HOUSE.

(iii) Because I SMOKED in the HOUSE.

As these examples show, gamble with a lawyer and smoke in the house, unlike hire a lawyer and sell my house, require separate accents on verb and noun. Crucially, the same accent patterns show up in pre-nuclear position: 
(36) A LAWYer I GAMBle with sent the REQUeSt to SMOKE in my House to their OFFICE.

And again, it seems to me that even if the question answered by (36) is 'Where did a lawyer you gamble with send the request to smoke in the house?', or 'What happened to the request to smoke in the house?', the answer as a whole sounds cumbersome, but does have to have the accents in the places indicated.

What we have seen, then, is that integration effects can be observed in the background as well as in focus, which argues that they should be captured not by the theory of focus projection, but by a theory of default prominence, which is independent of focus.

Before closing, let me again address two conceivable reactions to this argument. The first is that the pre-nuclear accents are not really obligatory in these examples, so that the very existence of default prominence without focus is questionable, undermining the idea that default prominence with focus should be reduced to it.

I doubt that this is correct: To find a sentence with a narrow, late focus such as (33) pronounced without prenuclear accents is rare, to say the least. But even if we did, this leaves the argument untouched, as long as we grant that narrow focus sentences can be pronounced with prenuclear accents, and that these accents are distributed in the way claimed here. The main point is that there are rules of default prominence that produce the integration patterns found within focus, whether or not those apply in every time we pronounce the sentence.

A second objection to the argument presented in this section could be that the pre-focus accents in the examples above, while not focus, are topic-accents (or contrastive topics, or some such thing), not just the result of default prominence. In reply to that, it should be noted that this objection, even if factually correct, merely weakens the point made here. If topic accents and focus accents are related to topic marking and F-marking, respectively, in identical ways, one conceivable conclusion is that syntactic F-patterns and syntactic T(opic) patterns are subject to the same syntactic projection rules. An alternative conclusion is, however, that these rules are simply not $\mathrm{F} / \mathrm{T}$ projection rules at all, but more general rules of prominence assignment, which is of course the conclusion argued for here.

In addition, however, I find it hard to see in which sense all the prenuclear accents in the examples discussed in this section could be argued to be topic accents, either prosodically or pragmatically. Typically, topic accents in English are assumed to be late rises with a characteristic fall-rise tail (e.g. $\mathrm{L}^{*}+\mathrm{H} \mathrm{L}-\mathrm{H} \%$ in ToBI notation), which is not what we find in the examples above. Likewise, I fail to see how, for example, all of the lawyer sent the request meets the pragmatic criteria for topic-hood under any of the common theories about topic 
marking. ${ }^{9}$

\subsection{A Simple Prominence-Based System}

In this subsection I will present a system of default prosody closely based on that in Truckenbrodt $(1995,1999)$ and its variants in Büring and Gutiérrez-Bravo (2001); Büring (2001a,b). This is a rather primitive system, which doesn't account for all the intricacies of integration in English, but is comprehensive enough to serve as an illustration. The system has two major components, one regulating default prosody, one factoring in focus. The latter is embodied by the constraint in (37):

(37) Focus Prominence (FP) (Truckenbrodt, 1995):

Focus needs to be maximally prominent.

A prosodic category $C$ that contains a focussed constituent is the head of the smallest prosodic unit containing $C$.

In the italicized part in (37), I indicate how exactly we are going to interpret Truckenbrodt's constraint for the present purposes. Crucially, prominence is defined on prosodic structures. I assume three levels of prosodic structures, the prosodic word, the accent domain, and the intonational phrase. Each prosodic word has a head, which is its word level stress position; for example, the umbrella forms one prosodic word, the head of which is umbrella (or rather, the syllable bre). Each accent domain has a head, which is the prosodic word within it that bears a pitch accent (whence the name). Each intonational phrase has a head, which is simply the rightmost accent domain within it. To be prominent within a prosodic domain (prosodic word, accent domain, intonational phrase) means to be the head of that domain.

Lastly, we will say of a prosodic unit that it is focussed if it contains a syntactic constituent that is F-marked. Returning to a single focus example, if the F-marked element is a word or a simple phrase such as my umbrella, the prosodic words containing it, written as $(m y \text { umbrella })_{P W d}$ will become the head of its accent domain (most prominent within accent domain), and that accent domain will become the head of its intonational phrase:

Q: What did Lesley sell?

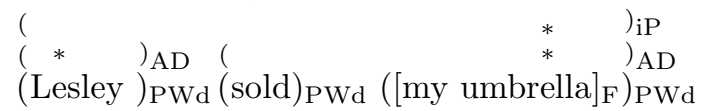

The final prosodic word in (38) is focussed (it contains an F-marked constituent). In accordance with FP (37) it is the head of its accent domain (indicated by the star on umbrella in the AD line), and that accent domain in turn is the head of intonational phrase (indicated by a star in the iP line ${ }^{10}$ ). Heads of accent

\footnotetext{
${ }^{9}$ Except of course those on which topic is simply the complement of focus, in which case topic prominence is default prominence.

${ }^{10}$ The star is on the brel syllable, though technically speaking the entire accent domain sold my umbrella is the head of intonational phrase.
} 
domains bear pitch accents, nothing else does.

We will not concern ourselves with the principles that govern the formation of prosodic words here. Roughly, any lexical head together with its functional 'entourage' forms a prosodic word. Accent domain formation is assumed to be governed by three constraints:

$$
\mathrm{ADJ}=\mathrm{AD} \gg * \text { STRESS PRED } \gg \mathrm{XP}=\mathrm{AD}
$$

a. ADJ=AD: Adjuncts form accent domains.

b. *STREss PReD: Verbs/ predicates/ heads don't bear prominence.

c. $\mathrm{XP}=\mathrm{AD}$ : XPs form accent domains.

As in Truckenbrodt's system, these constraints are crucially ranked. For example (38), ${ }^{*}$ Stress Pred and $\mathrm{XP}=\mathrm{AD}$ are important. $\mathrm{By} \mathrm{XP}=\mathrm{AD}$, the subject, the object, and the VP want to be accent domains. By *Stress Pred, the verb alone does not. Grouping it together with the object violates $\mathrm{XP}=\mathrm{AD}$ once (the object doesn't form its own accent domain), but satisfies *STRESS PrED, which is the higher ranked constraint. Any other grouping would violate $\mathrm{XP}=\mathrm{AD}$ at least twice, as the reader may verify.

What if the same sentence has focus on V ('What did Lesley do to your umbrella?')? The resulting structure would be (40):

$$
\left.\stackrel{(*)}{(*})_{\text {AD }}(\stackrel{*}{(\text { Lesley }})_{\mathrm{PWd}}\left(\text { sold }_{\mathrm{F}}\right)_{\mathrm{PWd}}(\text { my umbrella })\right)_{\mathrm{PWd}}
$$

Here, the PWd sold becomes the head of its accent domain, and that accent domain becomes the head of its intonational phrase, in accordance with FP in (37). This structure violates *STREss PRED in making $\mathrm{V}$ the head of an accent domain, which results in a pitch accent; but note that FP would be violated in a structure like (38) above, in which the object becomes the head of its accent domain:

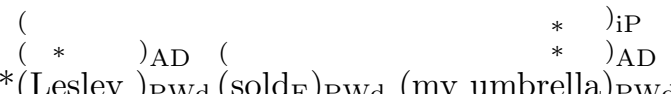

Focus Prominence, then, must be ranked higher than any of the constraints in (39). It 'overrides' default prosodic structure.

Note at this point already that there is only one violation of FP in (41), not two. The PWd containing the focussed $\mathrm{V}$ is not the head of its accent domain; that's the violation. But the accent domain containing the focussed V is the head of its intonational phrase. No additional violation is incurred by the fact that the nuclear pitch accent, not just a secondary pitch accent, falls on a non-focussed element.

This technical detail becomes crucial in the analysis of wider foci, as in the answer to 'What did Lesley do?': 


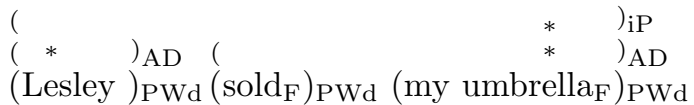

Here, V and the object NP are F-marked, hence want to become the head of their accent domain; therefore, one violation of $\mathrm{FP}$ is inevitable. If $\mathrm{V}$ becomes the head, *STREss PRED is violated in addition, if the object becomes the head, only $\mathrm{XP}=\mathrm{AD}$ is (since the object doesn't form its own accent domain); since *Stress Pred is the higher constraint, the latter structure is chosen. Note once again, that the fact that $\mathrm{V}$ is neither the head of its accent domain nor of it intonational phrase only results in one violation of FP, just as in (41) above.

One may be tempted to think that (43) would be a better solution to the problem of having two F-marked constituents:

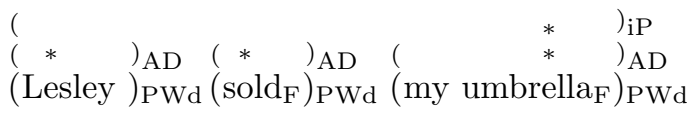

Here, $\mathrm{V}$ is at least the head of an accent domain, though it is not the head of the intonational phrase. Isn't that better? No, since the accent domain headed by $\mathrm{V}$ is not the head of the intonational phrase. Therefore, one violation of FP occurs, just as before, only at a 'higher level' (intonational phrase instead of accent domain), as it were. And among the two structures violating FP once, (42) is preferable since it doesn't violate *STRESS PRED to boot.

In sum, the integration effect generally results from the fact that predicate+argument (with the argument as the head of the accent domain) is a better accent domain than a predicate alone. Focussing both doesn't change that, since one of the two will be less prominent than the other at some point; the question is simply whether at the accent domain or at the intonational phrase level, and so again, ${ }^{*}$ Stress Pred decides the issue.

Let us lastly look at a case involving an adjunct:

Q: What did Lesley do?

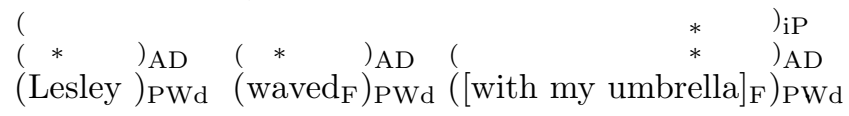

Here, verb and adjunct (with my umbrella) do not integrate, resulting in a pitch accent on the verb, in addition to the adjunct. This follows form the present system simply because the constraint $A D J=A D$ is ranked even higher than ${ }^{*}$ STREss PRED. Accordingly, a structure in which verb and adjunct form one accent domain, while satisfying the latter, fatally violates the former.

So while in (44), too, one F-marked constituent will ultimately violate FP by being 'subordinated' to the other, the point at which this happens in this example is 'higher', since the default constraints favor a structure in which the adjunct forms its own accent domain over one in which the predicate integrates with it. (The same will happen if two argument XPs are F-marked, since no constraint parallel to ${ }^{*}$ STRESS PRED favors their integration). 
Quite generally we see here how the integrate/don't integrate divide is encoded in the formal system: Configurations that prohibit integration are ranked for accent domain status above ${ }^{*}$ STRESS Pred, configuration in which integration can happen are ranked below it.

The mini-system presented in this section thus derives the basic facts about horizontal focus projection from default prominence rules. Obviously, these rules are quite primitive and call for various refinements. Perhaps foremost among them is some account for the semantic factors that influence integration. It has been observed that not all predicate-argument combinations integrate alike. Intransitive individual level predicates, but also certain transitive verbs are much less amenable to integration (cf. examples (35) and (36) above), something the present proposal doesn't account for. ${ }^{11}$ So presumably, semantics (or pragmatics) influences default prominence; the important point is that its effects, whatever they are exactly, influence prominence with and without focus alike, which is our main reason for divorcing integration from FP. The rules given in this section suffice to show how a system that combines default prominence with focussing derives adequate results without invoking horizontal focus projection.

\section{Conclusion}

In section 3 we saw that the restrictions on vertical focus projection built into the standard focus projection rule are empirically inadequate: F-marking on XP does not require an accent on $\mathrm{X}^{0}$ or a complement of $\mathrm{X}^{0}$; any accent within $\mathrm{XP}$ can project focus. In section 4 we then presented an argument for thinking that the main effect of horizontal focus projection, integration, should be thought of as a consequence of default prominence assignment, not focus projection; we then presented a small system that illustrated how default prominence assignment and focus interact in the manner desired. Together, these two arguments pave the way for a theory without any focus projection rules. The only rule required is $\mathrm{FP}$, repeated here:

(45) Focus Prominence (FP) (Truckenbrodt, 1995):

Focus needs to be maximally prominent.

$A$ prosodic category $C$ that contains a focussed constituent is the head of the smallest prosodic unit containing $C$.

It should be noted that (45) almost subsumes our earlier rule (31) from section 3, which required that any non-terminal bearing an F-mark must dominate another F-marked category. (45) is slightly more liberal than that in that it doesn't even require there to be an F-mark dominated by the higher F. In other words, a

\footnotetext{
${ }^{11}$ These cases should be kept distinct form those in which the object simply isn't F-marked, so that the verb becomes the head of the accent domain. I suspect that many cases involving definite and in particular pronominal objects are of this type, since these are easily accommodated to be Given.
} 
complex constituent $\mathrm{X}$ which itself only contains Given material could be Fmarked by (45), with the accent within $\mathrm{X}$ determined by default prominence. According to our earlier rule, there would have to be at least one F-mark on a terminal node within X. I assume that (45) is the correct choice, but see the discussion in the appendix.

\subsection{Comparison to the Standard View}

How does the system sketched here compare to the standard view? First, if the empirical arguments presented in section 3 are correct, the present system is more adequate in allowing for vertical focus projection from adjuncts, specifiers, and minor categories, as well as from individual conjuncts in coordinations.

Since the account of accent domain formation given was rather primitive, it seems premature to compare its predictions about where integration happens to those of the standard view; they are equivalent for the main cases (verbs, objects, subjects, adjuncts), but may differ in more intricate examples.

Second, and crucially, however, the present system also accounts for accent placement outside of the focus, i.e. preceding it. Such 'ornamental accents' are not allowed in the standard view, since by the Basic Focus Rule (1) an accented word is F-marked. On the present account, default prosody will occur wherever it isn't 'overridden' by focussing. In practical terms this means that default prosody will automatically show up prefocally, but never post-focally. This is because the rightmost accent domain is by definition the head of the intonational phrase. The head of the intonational phrase is more prominent than any nonhead. Therefore, the head of the intonational phrase must itself be focussed. The net effect is that the rightmost accent domain must be focussed, but any accent domain preceding it need not be. While this empirical pattern is wellknown, the standard view, and to the best of my knowledge any account prior to Truckenbrodt $(1995,1999)$ fail to derive it systematically, and the present proposal is presumably the first to discuss its interaction with focus projection in English in significant detail.

Apart from these empirical advantages, the present system gets rid of focus projection rules, which may be considered desirable (Occam's razor etc.). It should be noted, though, that various new rules to regulate default prominence were introduced in turn. I think the argument lies in the broader coverage of those as opposed to the original horizontal focus projections, not in the fact that we don't call them focus projection rules any more.

There is an argument from parsimony lurking though, if we ask ourselves what purpose the F-markers play on the present view. Since none of the rules of default prominence make reference to F-features, it seems to me we can suspend these features altogether by simply conflating the focus interpretation rules with FP. Instead of (5) above, we could have (46):

(46) Prominence Interpretation:

a. If a constituent is not Given, it must be prominent. 
b. If a constituent corresponds to the $w h$-phrase in the question under discussion, it must be prominent.

A constituent $\mathrm{C}$ is prominent iff the smallest prosodic constituent $\mathrm{P}$ containing it is the head of the next higher prosodic constituent containing $\mathrm{P}$.

These rules are a little cumbersome, but they subsume the original focus interpretation rules and the effect of focus prominence, while effectively eliminating the notion of F-marking. Note that this result is not tied to the particular focus interpretation rules given here (Givenness and question-answer congruence); most, if not all focus interpretation rules that have been proposed in the literature can be rewritten in this way. So while we may choose to retain F-marking as a matter of convenience, the present system makes it in effect obsolete (I don't believe a similar rewriting is possible in the standard view); in that sense, it can be said to be more parsimonious, too. ${ }^{12}$

\subsection{Comparison to Schwarzschild (1999)}

As pointed out at the beginning of this paper, the view explored here is very similar to that in the final section of Schwarzschild (1999), and many of the arguments presented can be seen as elaborations of suggestions made there. The main empirical difference lies in the more sophisticated approach to default prominence adopted here. Schwarzschild (p.173) merely requires that any FOC-marked constituent (i.e. any F-marked constituent not immediately dominated by another F-marked constituent) contain an accent. The only default prominence rule invoked is one preventing a head from being more prominent than its internal argument. With this in mind, consider (48):

(48) Q: What did you do (to make him so angry)?

A: I [introduce $F$ his friend ${ }_{F}$ to a bassoon player $_{F}$ from the island $]_{F}$.

As indicated, any element within the VP, as well as VP itself must be F-marked (nothing pertinent is Given), which makes VP the only FOC-marked element. So VP must contain an accent, and that accent must not be on the verb. This leaves open various other possibilities; in particular, one accent on either friend or bassoon player or island should suffice to realize this structure. The correct result, however, is one where each of these words bears an accent. On the present account, this will follow, since they are F-marked, and hence, by FP, must be prominent, and prominence of an entire phrase always implies accenting that phrase.

Perhaps one could argue that while friend, bassoon player and island are Fmarked, their maximal projections are not; that would make all these F-marks FOC-marks, forcing additional accents. But the same general argument could

\footnotetext{
${ }^{12}$ Of course, there have been earlier proposals to get rid of focus projection rules in the literature, most recently in Reinhart (1995); that system, however, is very different from the present one, and a detailed comparison has to await a later occasion.
} 
be made using (49):

I [introduced ${ }_{F} \operatorname{John}_{F}$ to Mary $]_{F}$

Now we would need to invoke non-branching projections to effectively make any F-marked phrase a FOC, an implausible step at best.

Could it be, on the other hand, that all the XPs within VP, but not VP itself is F-marked? In that case, each F-marked XP will qualify as a FOCus and receive an accent. But by the same token, the verb, too, qualifies as FOCus and should be accented as well, contrary to fact.

It seems that Schwarzschild's system generally is too unrestrictive when it comes to predicting accent placement within larger stretches of F-marked constituents. The present system, by using more sophisticated rules of default prominence, overcomes this problem and maintains, among other things, the 'focus contains accent' property.

In sum, then, we follow (and extend) the general argument in Schwarzschild (1999) that vertical focus projection is syntactically unconstrained, and that horizontal focus projection is better conceived of as a result of default prominence, which taken together imply that F-marking is dispensable with. Unlike Schwarzschild, we use a more elaborate system of default prominence that accounts more adequately for accent placement within larger foci, and moreover captures default prosody in pre-focal structures.

\section{Appendix: More on Default Prominence}

When we presented our argument that horizontal focus projection is really just default prominence, we concentrated on showing that prominence pattern preceding focus show the integration effect, too. As briefly hinted at at the beginning of section 5, another configuration to look at is one where a non-terminal, F-marked node X exclusively dominates Given material, so that the actual accent placement within $\mathrm{X}$ is regulated by default prominence alone. Here's a pertinent example from Schwarzschild (1999), p.172:

(50) (The rising of the TIDES depends upon the MOON being full, and) [the MOON being full $]_{F O C}$ depends upon [the position $F$ of the $\left.\mathrm{SUN}_{\mathrm{F}}\right]_{\mathrm{FOC}}$.

The second occurrence of the moon being full must be F-marked (since it is not Given that the moon being full depends on anything), but all its sub-constituents are Given. A question-answer example illustrating a similar situation is answer A in (51):

(51) Q: What did Sue do when you called Bill's sister?

A: Sue [called BILL] $]_{\text {FOC }}$.

A': Sue [SCREAMED $]_{\text {FOC }}$. 
In the MOON being full as well as in called BILL, the accent falls on the argument, rather than the predicate, as predicted by default prominence rules. Schwarzschild assumes that this involves assignment of a 'gratuitous' F-mark on moon/Bill, since by the Basic Focus Rule, only F-marked terminals can be accented. We saw in section 4, however, that F-less terminals can be accented, resulting in what we called ornamental accents. Ornamental accents can be assigned in keeping with default prominence, if they don't result in an unfocussed element being more prominent than a focussed one. In answer A in (51), there are three prosodic words, she, called and Bill. Since none of them is F-marked, it doesn't matter which becomes the head of an accent domain, and by default prominence, we get two accent domains $(\text { Sue })_{A D}\left(\right.$ called Bill) ${ }_{A D}$, where the head of the second one is the prosodic word $(B i l l)_{P W d}$. Now, the second accent domain also is focussed, since it contains the F-marked VP, and accordingly must become the head of the intonational phrase.

Similarly, of the tides in (50) is a more prominent prosodic word than the rising, which is okay by FP, since neither one is focussed. The accent domain the rising of the tides does contain a focus, but so does the last accent domain of the sun, so we get the familiar pattern here, too.

It seems, then, that we can take these cases, too, to provide arguments for default prosody, though presumably, contra to Schwarzschild (1999), they don't involve F-marks triggered by purely structural demands.

A slightly different take on these cases, however, would assume that they do nonetheless involve F-markings, licensed by more local contrasts. Consider (52):

Q: Who did Liv's mother meet at Astrid's house?

A1: She met $[\text { Astrid's MOTHER }]_{\mathrm{FOC}}$.

A2: She met [ASTRID's mother $]_{\mathrm{FOC}}$.

Astrid and mother are both Given. Extending the above line of thought, we would expext default prominence to kick in in such a case. What we do find, however, are two equally acceptable and natural patterns. Intuitively, Astrid's mother in A1 is contrasted with Astrid's houese in the question, while in A2 it is contrasted with Liv's mother. Whatever the technical implementation, at least one of these patterns can not be a matter of default prominence, but of discourse pragmatics, and hence involve F-marking. But if we grant that, then what should stop us from thinking that in both cases we are dealing with additional F-marking on a Given element, rather than default prominence?

Similar stories could be told about (51): called Bill contrasts with called Bill's sister. Though no such story comes to mind immediately for Schwarzschild's the moon being full/the rising of the tides example, I conclude at this point that accent distribution among Given elements within a FOCus may provide an argument for default prominence, but that closer scrutiny is required. 


\section{References}

Abraham, Werner, and Sjaak de Meij. 1986. Topic, Focus and Configurationality. Amsterdam: John Benjamins.

Altmann, Hans. 1988. Intonationsforschungen. Tübingen: Niemeyer.

Bosch, Peter, and Rob van der Sandt. 1994. Focus and Natural Language Processing. 3 Volumes. IBM Deutschland GmbH.

—. 1999. Focus - Linguistic, Cognitive, and Computational Perspectives. Cambridge University Press.

Büring, Daniel. 1996. On (De)Accenting. Talk presented at the SFB 340 conference in Tübingen, October.

Büring, Daniel. 2001a. Let's Phrase It! - Focus, Word Order, and Prosodic Phrasing in German Double Object Constructions. Müller and Sternefeld (2001), 101-137.

-. 2001b. What do Definites do that Indefinites Definitely don't? Féry and Sternefeld (2001), 70-100.

Büring, Daniel. submitted. Intonation, Semantics, and Information Structure. Interfaces, edited by Gillian Ramchand and Charles Reiss. Oxford University Press.

Büring, Daniel, and Rodrigo Gutiérrez-Bravo. 2001. Focus-related word order variation without the NSR: A prosody-based crosslinguistic analysis. Syntax at Santa Cruz 3, edited by Séamas Mac Bhloscaidh, 41-58.

Delin, Judy, and Ron Zacharski. 1994. A conversational model of information structure and intonation. Bosch and van der Sandt (1994), 61-70.

Drubig, Hans Bernhard. 1994. Island Constraints and the Syntactic Nature of Focus and Association with Focus. Tech. Rep. 51, Tübingen.

É. Kiss, Katalin. 1998. Identificational Focus and Information Focus. Language 74:245-273.

Féry, Caroline, and Wolfgang Sternefeld. 2001. Audiatur Vox Sapientiae: A Festschrift for Arnim von Stechow. No. 52 in studia grammatica. Akademie Verlag.

Fintel, Kai von. 1994. Restrictions on Quantifier Domains. Ph.D. thesis, UMass, Amherst.

Fuchs, Anna. 1976. Normaler und kontrastiver Akzent. Lingua 38:293-312.

Gussenhoven, Carlos. 1983. Focus, Mode, and the Nucleus. Journal of Linguistics 19:377-417. Reprinted as chapter 1 in Gussenhoven (1984). 
-. 1984. On the Grammar and Semantics of Sentence Accents. Dordrecht: Foris.

—. 1992. Sentence Accents and Argument Structure. Roca:1992, 17-106.

-. 1999. On the Limits of Focus Projection in English. Bosch and van der Sandt (1999), 43-55.

Jacobs, Joachim. 1988. Fokus-Hintergrund-Gliederung und Grammatik. Altmann (1988), 89-134.

—. 1991/2a. Informationsstruktur und Grammatik. Opladen: Westdeutscher Verlag. (= Linguistische Berichte Sonderheft 4).

—. 1991/2b. Neutral Stress and the Position of Heads. Jacobs (1991/2a), 220244.

—. 1992. Integration. Tech. Rep. 14, SFB 282, Düsseldorf, Köln \& Wuppertal.

-. 1999. Informational Autonomy. Bosch and van der Sandt (1999), 56-81.

Müller, Gereon, and Wolfgang Sternefeld, eds. 2001. Competition in Syntax. No. 49 in Studies in Genitive Grammar. Berlin \& New York: de Gruyter.

Reinhart, Tanya. 1995. Interface Strategies. OTS Working Papers.

Rochemont, Michael. 1986. Focus in Generative Grammar. Amsterdam/Philadelphia: John Benjamins.

Rooth, Mats. 1992. A Theory of Focus Interpretation. Natural Language Semantics 1:75-116.

Schmerling, Susan F. 1976. Aspects of English Sentence Stress. Ph.D. thesis, Austin.

Schwarzschild, Roger. 1999. GIVENness, AvoidF and Other Constraints on the Placement of Accent. Natural Language Semantics 7:141-177.

Selkirk, Elisabeth. 1984. Phonology and Syntax: The Relation between Sound and Structure. Cambridge, Mass.: MIT Press.

—. 1995. Sentence Prosody: Intonation, Stress, and Phrasing. The Handbook of Phonological Theory, edited by John A. Goldsmith, 550-569. London: Blackwell.

Truckenbrodt, Hubert. 1995. Phonological Phrases: Their Relation to Syntax, Focus, and Prominence. Ph.D. thesis, MIT. Published 1999 by MITWPL.

-. 1999. On the Relation between Syntactic Phrases and Phonological Phrases. Linguistic Inquiry 30:219-255.

Uhmann, Susanne. 1991. Fokusphonologie. Tübingen: Niemeyer. 
van Deemter, Kees. 1999. Contrastive Stress, Contrariety, and Focus. Bosch and van der Sandt (1999), 3-17.

von Stechow, Arnim, and Susanne Uhmann. 1986. Some Remarks on Focus Projection. Abraham and de Meij (1986). 